Canadian Studies in Population, Vol. 35.1, 2008, pp. 49-71

\title{
Quality of Care and Mortality among Long-term Care Residents with Dementia
}

\author{
R. Colin Reid \\ Health Studies \\ University of British Columbia Okanagan \\ 3333 University Way \\ Kelowna, BC, V1V 1V7, Canada \\ colin.reid@ubc.ca
}

\begin{abstract}
Seniors with dementia who enter long-term care facilities are at greater risk of death than are similar individuals that remain in the community. Previous research has focused primarily on social selection factors such as health status to explain mortality in this population. This study seeks to determine whether resident mortality within 12 months of admission to a facility can be explained by post-admission social causative factors, that is, by institutional quality of care. Logistic regression results are based on the study of 402 residents in 73 long-term care facilities throughout British Columbia, Canada. Mortality data were obtained from Vital Statistics. Although social selection factors (e.g., physical dependency) emerge as the strongest predictors, one social causative factor - facility level restraint use - also predicts mortality. This study provides some evidence that social causative factors play a role in determining mortality among long-term care residents with dementia. Further research on the social causative factors is needed to understand the degree to which they affect mortality, and the way in which they do so.
\end{abstract}

Key Words: Dementia, social causative factors, social selection factors, longterm care, mortality 


\section{Résumé}

Les personnes âgées atteintes de démence qui entrent en établissements de soins de longue durée encourent un risque plus élevé de décès que d'autres personnes souffrant de manière similaire mais qui demeurent au sein de leur communauté. Jusqu'à présent la recherche s'est surtout intéressée aux facteurs de sélection sociale tels que l'âge, le genre, et l'état de santé, pour expliquer le taux de mortalité au sein de cette population. L'étude présente cherche à déterminer si la mort d'un résident dans les 12 mois qui suivent l'admission dans un établissement peut être expliqué par des facteurs causals sociaux survenant après leur admission, et qui seraient donc liés à la qualité des soins dans les institutions. Les résultats de régression logique sont basés sur une étude de 402 résidents dans 73 établissements de soins de longue durée en ColombieBritannique au Canada. Les données sur la mortalité ont été obtenues par Vital Statistics BC. Bien que les facteurs de sélection sociale (âge, genre, et dépendance physique) émergent comme étant de bons prédicteurs, il a été trouvé qu'un facteur causal social - l'usage de contentions dans les établissements détermine aussi le taux de mortalité. Cet article offre pour preuve que les facteurs causals sociaux jouent un rôle dans la détermination des causes de mortalité au sein des résidents d'établissements de soins de longue durée souffrant de démence. Il est nécessaire de continuer cette recherche pour comprendre à quel point ces facteurs influencent le taux de mortalité et en quelle façon.

Mots-clés : Démence, facteurs causals sociaux, facteurs de sélection sociale, soins de longue durée, mortalité

\section{Introduction}

As the Canadian population continues to age, the number of persons with dementia grows apace. Of equal concern is the projected increase in the number of persons with advanced dementia due largely to the increase in the size of the old old (85+) population (Hill, Forbes, Berthelot, Lindsay, \& McDowell, 1996). One-half of all people living in long-term care institutions have Alzheimer's disease or other dementias (Canadian Study of Health and Aging, 1994). While informal, non-institutional care is preferred by most, the reality is that long-term institutional care will be required by many more severely demented seniors than has been the case in the past. While there are differing views on the appropriate allocation of scarce public funds, the question of how best to care for such persons is a pressing, though complex, matter. Despite overriding cost 
considerations, there is a fundamental ethical concern for the maintenance of dignity, health and quality of life in general for persons afflicted with dementia who require institutional care. The issue becomes one of identifying precisely what quality of care is needed to effectively care for an increasingly frail and demented institutional population (Shaughnessy \& Kramer, 1990; USGAO, 1983). Effective caring requires an understanding of the outcomes, including mortality, that may result from any given care regime

Previous research has identified essential indicators of quality of care (e.g. Holmes et al., 1994), and subsequent research has attempted to establish the effects of quality of care on key quality of life outcomes (Chappell \& Reid, 2000; Phillips et al., 1997; Saxton, Silverman, Ricci, Keane, \& Deeley, 1998). Length of survival of the institutionalized dementia sufferer is conspicuously under-researched, yet survival time is considered an important indicator of quality of care for persons with late stage dementia, one that may be affected by treatments and health service interventions (Spector \& Mukamel, 1998; Teno, Landrum, \& Lynn, 1997). Survival time is among the thirteen outcomes recommended for study by Teno and associates (1997) for persons with endstage dementia. Previous research has established that persons with dementia entering long-term care facilities experience excess mortality when compared to similarly demented individuals remaining in the community (Aneshensel, Pearlin, \& Schuler, 1993; Aneshensel, Pearlin, Mullan, Zarit, \& Whitlatch, 1995; van Dijk, van de Sande, Dippel, \& Habbema, 1992). However, the reasons for this excess mortality are not fully understood: it is only partially due to the selective admission of persons at higher risk of death (Aneshensel, Pearlin, Levy-Storms, \& Schuler, 2000). According to Aneshensel and associates (1995: 262), "institutionalization per se is substantially associated with the risk of dying over and above the effects of poor physical health."

The question becomes: What is it about institutionalization that results in greater risk of death? Some research suggests that better general quality of care is linked to lower mortality among long-term care residents (e.g. Bell \& Krivich, 1990; Weiler \& Cooper, 1990), and that more aggressive care plans result in longer survival times for persons with severe dementia (Luchins, Hanrahan, \& Murphy, 1997). The purpose of this paper is to determine whether mortality among longterm care residents with dementia is dependent, at least in part, on the quality of care delivered by the institution.

\section{Literature Review}

The occurrence of excess mortality among the institutionalized elderly is well documented. Excess mortality can be defined as actual deaths minus expected 
deaths (van Dijk et al., 1992). Explanations for excess mortality observed among long-term residents have typically focused on health differences between institutionalized and noninstitutionalized older persons. In other words, frailer individuals who are at greater risk of death in the first place are more likely than healthier individuals to enter long-term care facilities, and thereafter to die at a faster rate than those remaining in the community. When the influence of dementia is considered, the picture becomes even more "self-evident". Dementia is an important predictor of both institutionalization and death following admission (Belloni-Sonzogni, Tissot, Teetamanti, Frattura, \& Spagnoli, 1989; Branch and Jette, 1982; Diesfeldt, van Houte, \& Moerkens, 1986; Greene \& Ondrich, 1990; Temkin-Greener \& Meiners, 1995).

Clearly, higher rates of death should be expected among the less healthy. This expectation receives support in the research literature, with resident characteristics emerging as important predictors of both death and institutionalization. Severe aphasia, urinary incontinence, severe dementia, severe mental abnormality, greater comorbidity, older age, need for intense nursing care, functional impairment, physical dependence, behavioural impairment, inactivity, and low levels of physical mobility have all been shown to be related to risk of death in the institutionalized population (Bracco et al., 1994; Brauer, Mackeprang, \& Bentzon, 1978; Bruce, Hoff, Jacobs, Leaf, 1995; Diesfeldt et al., 1986; Engle \& Graney, 1993; Goldfarb, 1969; Kelman \& Thomas, 1990; Lichtenstein, Federspiel, \& Schaffner, 1985; Shapiro \& Tate, 1988; van Dijk, Dippel, \& Habbema, 1991; van Dijk et al., 1992). Studies of the predictors of institutionalization give a similar impression (e.g. Beland \& Zunzunegui, 1999; Tomiak, Berthelot, Guimond, \& Mustard, 2000). It is thus no surprise that persons with dementia who are admitted to long-term care facilities are at greater risk of death than are those remaining in the community, and that it has been generally assumed that the higher rates of mortality (or "excess mortality") in this population are due entirely to characteristics that residents possess at admission.

This explanation is consistent with the "social selection" hypothesis, which states that excess mortality among newly admitted residents is the result of their greater illness and frailty (when compared to individuals remaining in the community). Research has in fact shown that such social selection does take place, and does account for a portion of the excess mortality observed in longterm care facilities, but does not explain it entirely. For example, in a four year longitudinal study of 5,151 persons aged 70 or more living in the United States, Wolinsky, Callahan, Fitzgerald, \& Johnson (1992) found that the risk of death increased by a factor of 2.74 following institutionalization, even after controlling for health status and other possible causes of mortality and institutionalization (see also Shapiro \& Tate, 1988; Wolinsky, Stump \& Callahan, 1997). Among 
those with Alzheimer's disease, Aneshensel et al (1993) calculated that, controlling for health status, the risk of death doubles following institutionalization. Van Dijk and colleagues (1992) found that death rates in a Dutch nursing home specializing in dementia care were three times greater for men and 2.4 times greater for women residents than for non-institutionalized population (some of whom had dementia). Similar findings are reported elsewhere (Nygaard \& Laake, 1990; Ostbye, Steenhuis, Wolfson, Walton, \& Hill, 1999). In short, health status alone does not account for the observed increase in mortality following admission to a long-term care facility.

In response, some researchers have attempted to isolate explanatory factors other than health status. Aneshensel et al. (1993) suggested that "social causation" may be an effective explanation of the observed excess mortality. In other words, something about the transfer to the institution, or something that happens following admission that is external to the resident has an effect on survival probabilities. In this view, the likelihood of survival is a function of the physical and therapeutic environment following admission, and only partly dependent, if at all, on social selection. Building on the findings of Aneshensel et al. (1993), Aneshensel et al. (1995) showed that excess mortality tends to occur within approximately 6 months of admission. Similar findings are reported elsewhere (Booth, Phillips, Barritt, Berry, Martin, \& Melotte, 1983; Costello \& Tanaka, 1961; Kane, Bell, Riegler, Wilson, \& Keeler, 1983; Porrell, Caro, Silva, \& Monane, 1998; Shapiro \& Tate, 1988; van Dijk et al., 1992). Aneshensel and associates (1995) established that rapid declines in survival rates were experienced, particularly during the first 3 months, among those admitted for poor health and among those admitted primarily for other reasons, including: the caregiver's belief that the dementia patient is potentially harmful to him or herself, or to others; the caregiver's assessment that he or she is no longer able to perform the tasks of caregiving, and; lack of sufficient assistance from others in performing care-related tasks. An observed mortality increase only among those in poor health would have constituted strong support for the social selection hypothesis. However, they concluded that although it is clear that social selection is an important explanation of excess nursing home mortality for those with dementia, a social causation explanation remains plausible.

A subsequent study by Aneshensel and colleagues (2000) again found that demented persons admitted to long-term care facilities experienced excess mortality, even after controlling for individual characteristics. They tested competing hypotheses, social causation and social selection, to explain the excess mortality among these long-term care residents. Some support for the social selection hypothesis was found. Residents with lower levels of cognitive functioning and whose caregivers cited poor patient health as a reason for admission were at greater risk of death than were those with higher levels of 
cognitive functioning and whose caregivers cited nonhealth-related reasons for admission. The authors did not find support for the social causation hypothesis, but point out that this may be due to the inadequacy of the measurement of quality of care. Their measures of quality of care consisted strictly of the informal caregiver's assessment of quality of medical care, quality of nursing and attendant care, problems with facility or staff, and satisfaction with the facility in general. The authors note that these variables do not represent the entire range of possible social contributors to premature death, and that they were all based on the assessment of the informal caregiver. They note specifically that, "the conditions that trouble or dismay caregivers may not be the conditions relevant to understanding morbidity and mortality among patients" (Aneshenel et al., 2000: S161). This leaves open the question of what it is about the experience following the move to institutional care that results in reduced survival times for residents, particularly during the first few post-move months. The purpose of this study is to determine the effect of quality of care, using state-of-the-art institutional care quality measures, on resident mortality during 12 months following admission.

Hypothesis. The higher the institutional quality of care as measured by the 6 crucial dimensions of care - flexibility of care, environmental design, admission and pre-admission procedures, physical restraints, pharmacological restraints, and staff education - the greater the probability of survival of a resident during the 12 month period subsequent to admission.

\section{Methods}

This study makes use of secondary data from the Intermediate Care Facility (ICF) Study. That study, its methodology and its measures are described in detail in Chappell and Reid (2000), and will therefore receive less detailed treatment here. The sample in the present study consists of 402 residents with dementia in long-term care facilities throughout the Canadian province of British Columbia (excluding northern BC). These 402 participants were derived from the original ICF study sample $(\mathrm{N}=510)$. Participants in the original sample that were not retained in the present analysis included residents who were transferred to other units in the same facility, to other facilities or were discharged home $(\mathrm{N}=79)$. Likewise, 26 residents in two facilities that were removed from the study due to fundamental changes in care quality provided by facilities during the course of the study, were omitted from the present study. Four individuals were removed from the study due to the length of time that elapsed between their discharge from the facility and their date of death. The 402 remaining residents lived in 73 long-term care facilities (50 special care units and 48 integrated units). Some facilities had both special care and 
Quality of Care and Mortality

Among Long-term Care Residents with Dementia

integrated units. Those newly admitted residents identified by Directors of Nursing as having moderate to severe dementia were screened for eligibility. Eligibility requirements included: a primary or secondary diagnosis of either Alzheimer's disease or vascular dementia; confirmatory evidence of dementia in their medical records; low risk of death within 12 months of admission; ability to communicate in English; 65 years of age or older. Consent for participation was obtained from responsible family members.

Data were collected in two phases. During phase 1, all facilities completed a comprehensive survey on six key dimensions of care, including: physical and chemical restraint use; flexibility of care; staff training and education; admission and preadmission procedures; and environment. During phase 2, outcome data were collected for participating residents from residents themselves, staff and families. Mortality data were obtained from the British Columbia Vital Statistics Agency. All residents participating in the ICF Project were tracked using Vital Statistics data, and death by month/year, and cause of death were provided. All measures used in the present study are discussed below (see Chappell \& Reid, 2000 for more detail).

\section{Measures}

Resident deaths were recorded by month of occurrence. Eighty-nine (22\%) of the 402 residents died within 12 months of admission. The six dimensions of care were each measured using multiple indicators. These measures, in addition to a measure of the intangibles of care (see below), comprise the social causation or quality of care variable. Table 1 provides variables descriptions.

\section{Environment}

Research assistants completed the Therapeutic Environment Screening Scale 2+ Instrument C (TESS) in each participating facility to measure the environmental dimension. The TESS is designed to "evaluate the appropriateness of a nursing home unit for residents with dementing disorders" (Sloane and Mathew, 1990).Possible total scores range from 1 to 154 (Cronbach's alpha=.82).

\section{Physical and Pharmacological Restraint Use}

Physical restraint use is measured by asking whether a facility used any of 11 specified physical restraints (ankle cuffs, bed rails, Dutch doors, geri-chairs, 
R. Colin Reid

Table 1

Variable Descriptions, Long-term Care Facilities, British Columbia: 1995-1999

\begin{tabular}{|c|c|c|c|}
\hline Variable & Mean or \% & SD & Coding \\
\hline Survival status (died) & $22.0 \%$ & - & $\begin{array}{l}0=\text { survived } 12 \text { months following admission; } 1=\text { died within } 12 \text { months } \\
\text { of admission. }\end{array}$ \\
\hline Chemical restraint use & 6 & 3.3 & $\begin{array}{l}\text { Number of following drugs used by facility for behavioural management } \\
\text { purposes in previous year: luvox, paxil, ativan, restoril, rivotril, xanax, } \\
\text { rivotril, xanax, haldol, loxapac, risperdal (0-9). }\end{array}$ \\
\hline Physical restraint use & 1.1 & 2.9 & $\begin{array}{l}\text { Number of following physical restraints used by facility in previous year } \\
\text { for behavioural management purposes: bedrails, geri-chairs }(0-2) \text {. }\end{array}$ \\
\hline Flexible care & 0.6 & 0.6 & $\begin{array}{l}\text { Does facility integrate activities into day to day care; Do support staff } \\
\text { receive instruction in activation techniques? }(0-2) \text {. } \\
\text { Higher means more flexible care. }\end{array}$ \\
\hline Specialized environment & 103.0 & 13.7 & $\begin{array}{l}\text { Therapeutic Environment Screening Scale: Quality of general design, } \\
\text { maintenance, lighting, noise, residents' rooms and programming } \\
\text { orientation are up to standard (1-154). Higher means better environment. }\end{array}$ \\
\hline Staff training/education & 321.2 & 166.3 & $\begin{array}{l}\text { Do registered nurses, LPNs, care aides and support staff receive training } \\
\text { or education in: general care for residents with dementia, management } \\
\text { of inappropriate behaviours, role of the family, stress reduction } \\
\text { techniques, safety issues, off-site training ( }(0-600) \text {. Higher means } \\
\text { more training/education. }\end{array}$ \\
\hline Pre-admission/admission & 2.0 & 0.9 & $\begin{array}{l}\text { Does facility use standardized preadmission and admission forms, } \\
\text { and are admission criteria in written form (0-3). Higher means } \\
\text { better pre-admission/admission procedures. }\end{array}$ \\
\hline Panel selection (gold) & $51.60 \%$ & - & $\begin{array}{l}\text { Would experts place selves or loved one in a Facility ( } 0=\text { no, facility is } \\
\text { not the best; } 1=\text { yes, facility is the best - gold standard). }\end{array}$ \\
\hline $\begin{array}{l}\text { Medical conditions (cancer } \\
\text { and/or heart disease) (yes) }\end{array}$ & $41.0 \%$ & - & $\begin{array}{l}\text { Does resident have a diagnosis of any form of cancer or heart disease } \\
(0=y e s ; 1=\text { no). }\end{array}$ \\
\hline Physical dependency & 11.4 & 7.5 & $\begin{array}{l}\text { Minimum Data Set } 2.0 \text { Item E: bed mobility, transfer between surfaces, } \\
\text { movement between locations, dressing, eating, toilet use, personal } \\
\text { hygiene, walking, bathing }(0-36) \text { higher score means greater dependency. }\end{array}$ \\
\hline Agitated behaviours & 24.3 & 8.5 & $\begin{array}{l}\text { Cohen-Mansfield Agitation Inventory - Short Form: Frequency of display } \\
\text { of } 14 \text { types of agitated behaviours in the previous week (14-70). } \\
\text { higher score means greater agitation. }\end{array}$ \\
\hline Affect & 41.0 & 7.1 & $\begin{array}{l}\text { Feeling Tone Questionnaire affect scale (16-80). } \\
\text { higher score means more negative affect }\end{array}$ \\
\hline Social skills & 10.0 & 1.9 & $\begin{array}{l}\text { MAS-R: Social skills retention and appropriateness }(0-11) \text {. higher score } \\
\text { means greater retention of social skills. }\end{array}$ \\
\hline Cognitive function & 6.8 & 5 & $\begin{array}{l}\text { MAS-R: Combined score of early memory and present orientation } \\
\text { scores }(0-22) \text {. Higher means better cognitive function. }\end{array}$ \\
\hline Age & 82.1 & 6.7 & Age in years (65-97) \\
\hline Gender (female) & $62.0 \%$ & - & $1=$ male $; 2=$ female \\
\hline Ownership status (private) & $49.0 \%$ & - & $0=$ private $; 1=$ public \\
\hline Percent with dementia & 78.8 & 24.3 & $(19-100 \%)$ \\
\hline
\end{tabular}

CSP 2008, 35.1: 49-71 
isolation, lap belt, posey vest, seclusion, sheet restraint, wrist restraint, and wheelchair tray) during the previous year for the management of behavioural difficulties. Pharmacological restraints were measured identically, with questions concerning the use of 17 commonly used psychotropic drugs in three categories (anti-depressants, anxiolytics and neuroleptics) during the previous year specifically for the management of behavioural difficulties. A factor analysis of all chemical and physical restraints produced two main factors: chemical and physical restraints. The largest factor (eigenvalue=5.75) included chemical restraints only and was comprised of the antidepressants Luvox and Paxil, the anxiolytics Ativan, Restoril, Rivotril and Xanax, and the neuroleptics Haldol, Loxapac and Risperdal. Facilities reported using a mean of 6.0 (s.d.=2.87) of these drugs for behavioural management purposes, with a range of $0-9$. Cronbach's alpha is .82 . The second factor (eigenvalue $=2.55$ ) included physical restraints only and was comprised of bedrails, geri-chairs and isolation. A reliability analysis showed that the inclusion of isolation in the scale reduced Cronbach's alpha from .66 to .31 . The measure for physical restraints therefore consists of two items: bedrails and geri-chairs. The mean number of restraints is 1.02 (s.d.=.86) and ranged from 0-2. This is in agreement with Sloane and colleagues (1997), who argue that chemical and physical restraints are separate dimensions. Unlike the other four dimensions, a higher score indicates poorer delivery of care.

\section{Flexibility of Care}

Flexible care routines were measured by two questions asking whether support staff receive instruction in activation techniques, and whether facilities integrate activities in day-to-day care. Scores ranged from 0 (facility does neither) to 2 (facility does both).

\section{Preadmission and Admission Procedures}

Preadmission procedures are intended in part to provide the best fit between resident and facility. Admission procedures should be geared to the move into the facility, and should furthermore facilitate effective care planning for each individual over the longer term following admission. These two procedures were combined into one care dimension since admission procedures can be viewed as a logical extension of preadmission procedures. Standardized forms based on existing, written criteria are considered to be good indicators of best practices in this area. The use of standardized forms for preadmission and admission procedures, combined with written criteria for admission is considered optimal for this dimension. Scores ranged from 0 to 3 . 


\section{Staff Training and Education}

Provision of training for registered nurses, licensed practical nurses, care aides and support staff was measured in the following 6 areas: general care for residents with dementia; management of inappropriate behaviours; role of the family; stress reduction techniques for staff; safety issues; and off-site training. Since only $40 \%$ of facilities employ licensed practical nurses, it was necessary to standardize for number of staff types employed. For each type of education, a proportion was calculated using number of staff types receiving each type of education as the numerator, and total staff types employed by the facility as the denominator. These scores were multiplied by 100 to produce a percentage score and the six scores were summed to create an education dimension. Scale range is 0-600 (alpha=.80).

\section{Intangibles}

In addition to the 6 objective measures of quality of care, a measure of the intangibles of care quality that may influence outcomes was added. Experts actively engaged in work on dementia care within institutional settings, and who were familiar with but not employed by the facilities participating in this study, were consulted. They were asked to provide a list of "gold standard" facilities. That is, they were asked where they themselves would want to live, or where they would place a loved one, should the need arise. Five such panels were convened, each representing a defined set of health regions within which a defined set of care facilities are located. All facilities in the study were represented. They were able to select gold standard facilities without difficulty. Thirty-nine of the 98 units included in the study were considered "gold" by the panel.

While the focus of this study is on the social causative factors that may affect mortality, variables representing alternative explanations are controlled for including age and gender (male $=0 ;$ female $=1$ ), in addition to physical dependency (Minimum Data Set 2.0 Item E) and health (no heart disease or cancer $=0$; heart disease or cancer $=1$ ) at admission to control for physical health at admission. Resident characteristics, behaviours and states at admission, in addition to four facility characteristics, are also included as controls. These include:

- agitation (Cohen-Mansfield Agitation Inventory - short form, CohenMansfield \& Marx, 1989) Range 14-70, Cronbach's alpha=.82. 
Quality of Care and Mortality

Among Long-term Care Residents with Dementia

- affect (Feeling Tone Questionnaire - Toner, J., Teresi, J. A., Gurland, B. J., \& Tirumalasetti, F., 1999) Range 16-80, Cronbach's alpha=.89.

- cognitive function [Multi-Focus Assessment Scale - Revised (MAS-R) Crockett, Coval, Tuokko, Buree, \& Koch, 1991] Range 0-22, Cronbach's alpha $=.87$.

- social behavioural skills (MAS-R) Range 0-11, Cronbach's alpha=.83.

- ownership status (public $=0$; private $=1$ )

- percent of residents with dementia, Range 19\%-100\%.

\section{Statistical Analysis}

Bivariate correlations are calculated between all independent and control variables and death status ( $\operatorname{did}$ not die $=0$; died $=1$ ). To test the study hypothesis, an analysis of the effect of quality of care on the occurrence of mortality using logistic regression is conducted and presented in Table 4. This will determine which, if any, of the dimensions of care - the social causation variables - have an effect on the occurrence or non-occurrence of death, controlling for the effects of the other variables outlined above. In order to test for interaction effects, each of the 6 dimensions of care was multiplied by each of the others to produce 15 cross-product terms. The interaction terms were correlated with death status, controlling for the constituent components of each respective interaction term, to determine whether an interaction effect was present. None of the interaction terms was significant in the multivariate analysis and therefore are not presented in the results.

\section{Results}

The sample consists of 402 cognitively impaired residents of intermediate care facilities throughout British Columbia. The mean age at admission was 82.1 years, and $62 \%$ were female. One fifth $(20.5 \%)$ were born in the province of British Columbia, almost half $(48.1 \%)$ were born elsewhere in Canada, $17 \%$ were born in the British Isles, and $14.3 \%$ were born elsewhere in the world. Most residents were affiliated with a religion, with $61.3 \%$ being Protestant, 13.8\% Catholic, $19.8 \%$ another religion, and $4.4 \%$ identified as having no religion. Forty percent were married, $48 \%$ were widowed, with the remainder being never married, separated or living with someone. The median income 


\section{R. Colin Reid}

range was $\$ 10,000-\$ 14,000$, with a range of $\$ 5,000$ to $\$ 75,000$ or more. Prior to admission to the facility, half $(50.6 \%)$ lived in their own homes and $26.9 \%$ lived in another long-term care facility. About $10 \%$ had previously been living in someone else's home or supportive/congregate housing, $8.9 \%$ had come from hospital, and $4 \%$ were transfers from a different unit in the same facility.

Of the 402 participants at time 1 (admission), 89 died prior to the end of the 12 month observation period. This represents a crude mortality rate of 220 per 1,000 per year. This is an extraordinarily high mortality rate when compared to that of the general Canadian population ( 7 per 1,000 per year). It is also high when compared to the crude death rates of 43 per 1,000 per year for persons aged 65 years and older, and 145 per 1,000 per year for those aged 85 years and older in British Columbia (averaged for the period 1995-1999 - calculated from data provided by the British Columbia Vital Statistics Agency, 2001).

Bivariate correlations between social causation, and all other variables, including death status (died or did not die) are presented in Table 2. Among the social causation variables, only facility level restraint use is correlated with death status $(\mathrm{r}=-.107) ; \mathrm{p}<.05)$. Greater physical dependency at admission $(\mathrm{r}=.157 ; \mathrm{p}<.01)$, poorer social skills at admissioin $(\mathrm{r}=.130 ; \mathrm{p}<.01)$, being male $(\mathrm{r}=-.155 ; \mathrm{p}<.01)$, and older age $(\mathrm{r}=.186 ; \mathrm{p}<.001)$ were related to greater risk of death. No other variables were related to risk of death at the bivariate level, including agitated behaviours, medical conditions, affect, cognitive function (all measured at admission), facility type and ownership status.

Logistic regression results are provided in Table 3 . The final model provides limited support for the study hypothesis. For each additional physical restraint (bedrail, geri-chair) a facility reports having used in the previous 12 months for the purpose of behavioural management, a resident is at $47.3 \%$ greater risk of death within 12 months of admission, when controlling for the effects of the other variables in the equation. Among other variables in the equation, each additional year of age of resident is associated with an increased risk of death of $8.8 \%$. Males are $13.1 \%$ more likely to die within 12 months of admission than are females and for each one point increase in the 36 point physical dependency scale, probability of death increases by $5.0 \%$. No other independent variables were related to death following admission. 
Table 2

Bivariate Correlations of independent and Control Variables with Death Status (died = 1; did not die =0) Long-term Care Facilities, British Columbia: 1995-1999

\begin{tabular}{lc}
\hline \multicolumn{1}{c}{$\begin{array}{c}\text { Independent/ } \\
\text { Control Variable }\end{array}$} & $\begin{array}{c}\text { Dependent Variable }= \\
\text { Death status }\end{array}$ \\
\hline \hline Chemical restraint use & -0.004 \\
Physical restraint use & $.107^{*}$ \\
Flexible care & 0.013 \\
Specialized environment & -0.007 \\
Staff training/education & -0.014 \\
Pre-admission/admission & 0.039 \\
Panel selection & 0.025 \\
Medical conditions & 0.055 \\
Physical dependency & $.157^{* *}$ \\
Agitated behaviours & 0.011 \\
Affect & 0.059 \\
Social skills & $-.130^{* *}$ \\
Cognitive function & -0.02 \\
Age & $.186^{* * *}$ \\
Gender & $-.155^{* *}$ \\
Ownership status & -0.047 \\
Percent with dementia & 0.023 \\
\hline
\end{tabular}

$* \mathrm{p}<.05 ; * * \mathrm{p}<.01 ; * * * \mathrm{p}<.001$ 
Table 3

Logistic Regression Results, Dependent Variable

Death Status (died - 1; did not die = 0)

Long-term Care Facilities, British Columbia: 1995-1999

\begin{tabular}{lcccc}
\hline \multicolumn{1}{c}{ Variable } & B & S.E. & Wald & Exp(B) \\
\hline \hline Chemical restraint use & -0.041 & 0.053 & 0.6 & 0.960 \\
Physical restraint use & $.388^{*}$ & 0.183 & 4.503 & 1.473 \\
Flexible care & -0.143 & 0.251 & 0.325 & 0.867 \\
Specialized environment & -0.003 & 0.010 & 0.082 & 0.997 \\
Staff training/education & 0.000 & 0.001 & 0.001 & 1.000 \\
Pre-admission/admission & 0.092 & 0.154 & 0.362 & 1.097 \\
Panel selection & 0.009 & 0.285 & 0.001 & 1.010 \\
Medical conditions & -0.021 & 0.271 & 0.006 & 0.979 \\
Physical dependency & $.048^{*}$ & 0.019 & 6.447 & 1.050 \\
Agitated behaviours & 0.003 & 0.017 & 0.018 & 1.002 \\
Affect & 0.008 & 0.020 & 0.093 & 1.006 \\
Social skills & -0.118 & 0.073 & 2.745 & 0.886 \\
Cognitive function & 0.029 & 0.032 & 0.912 & 1.031 \\
Age & $.082^{* * *}$ & 0.021 & 15.743 & 1.088 \\
Gender & $.766^{* *}$ & 0.270 & 7.88 & 2.131 \\
Ownership status & 0.159 & 0.281 & 0.319 & 1.172 \\
Percent with dementia & 0.005 & 0.006 & 0.643 & 1.005 \\
Constant & -8.988 & 2.489 & 13.038 & 0.000 \\
\hline & & & & \\
\hline Par & & & & \\
\hline
\end{tabular}

${ }^{*} \mathrm{p}<.05 ; * * \mathrm{p}<.01 ; * * * \mathrm{p}<.001$

Model summary: Cox \& Snell R square: .11 Nagelkerke R square: .17 -2LL: 380.424

Percent of cases classified correctly 80.0 
Quality of Care and Mortality

Among Long-term Care Residents with Dementia

\section{Discussion}

This study is an assessment of the effect of quality of care, or of social causative factors, on the risk of death among intermediate care facility residents with dementia. Care quality is measured along 6 dimensions as identified in the literature, in addition to a subjective assessment by panels of experts who were asked to identify which facilities could be considered the best, or the "gold standard" facilities. The six dimensions of care include: assessment procedures; non-use of physical restraints, non-use of chemical restraints, flexibility of care, staff training and education, and facility environment. It was expected that each of the care dimensions would exert an effect on the risk of resident within 12 months of admission, with better quality of care being associated with lower risk of death. These are construed as the social causative factors and their effects were expected over and above the effects of social selection variables such as health of residents.

Among the social causative factors, only facility level restraint use was found to be associated with the risk of death in the multivariate model. Residents of facilities that use more physical restraints for behavioural management purposes tend to be at higher risk of death. The reason for this may be seen as emanating from several, interrelated causes. Deaths can occur directly from the application of physical restraints. For example, Miles and Irvine (1992) report that at least 1 in every 1,000 deaths in nursing homes in Minnesota is directly caused by restraint use. They based their argument on an investigation that showed that deaths due directly to restraints are substantially under reported and under recognized. Although the present study neither sought not found any such direct evidence, it remains a plausible explanation for some deaths that did occur.

Another causal mechanism through which increased physical restraint use may adversely affect risk of death is the reduction in individuality and dignity that accompanies the application of restraints. The essence of the argument is that regardless of the physical and mental states of an individual, there remains a residual store of sense of self that can be damaged during episodes of restraints (Bradley, Siddique, \& Dufton, 1995). On the whole, individuals subjected to the indignity of physical restraint and who are already old, frail and vulnerable, will eventually be more likely to succumb to death with the addition of this final insult. It has been shown repeatedly that the removal of physical restraints does not lead to increased falls and fall related injuries (Capezuti, Strumpf, Evans, \& Maislin, 1999). It follows that deaths occurring due to these causes would not increase with a reduction in physical restraint use. In fact, better odds of survival might be expected, since the affected individual may retain a greater sense of self worth and dignity in the absence of restraints. Furthermore, the removal of 


\section{R. Colin Reid}

restraints would require a more individualized approach to care for that individual, which in and of itself is thought to be beneficial (Coulson, 1993).

A third potential explanation of the relationship between restraint use and risk of mortality is that facility level restraint use may stand as an indicator of something else within the facility. For example, it may stand as an indicator of facility ambience, social atmosphere, or some other unmeasured causal factor(s). Of the variables used in the multivariate model in this study, it could be argued that physical restraint use may be indicative of something less tangible in the social atmosphere. It seems likely that the administrative philosophy of care would be reflected in the propensity to use restraints. Furthermore, the social atmosphere or ambience of the facility could be reflected in and reinforced by the use of physical restraints. That is, unlike pharmacological restraints, physical restraints are visible to staff, visitors, and other residents. Also unlike with pharmacological restraints, a resident often knows that they are being restrained. Thus it is plausible that facility level physical restraint use may be an indicator of some other factor or factors that play some role in determining risk of death of some residents. Linn, Gurel and Linn (1977) argue similarly that RN hours and meals services ratings are in and of themselves less important in determining resident mortality risk than as a representation of intangibles that come into play once a certain threshold of structural care quality has been achieved.

Although one relationship between a quality of care variable and risk of mortality was evident in this study, the most important result is the general lack of relationships. Of note is that chemical restraint use is unrelated to risk of death. This might be explained by the nature of these types of restraints. Physical restraints are visible, uncomfortable in cases where a resident resists their application, and tangible. They are a potential identifiable source of embarrassment and indignation for the person so encumbered, and may contribute to a general sense of helplessness and hopelessness. An individual so distressed may be at greater risk of death, particularly in cases where the person is resistive and is at least partially aware that they oppose the application of any such mechanisms. Chemical restraints, on the other hand, would likely have the opposite effect. They are identified in this study as psychotropic medications anxiolytics, antidepressants and neuroleptics - used for the specific purpose of behavioural management. These drugs are designed to manage symptoms of anxiety and depression generally and, unlike physical restraints, are more likely to have a calming effect. While this does not appear to translate into a barrier against risk of death, it stands in marked contrast to the direct effect of increased physical restraint use. 
Two ascribed resident characteristics stand out, as they do in the general population, as predictors of death. Male and older residents are at greater risk of death. Greater resident physical dependency also results in greater probability of death following admission. Similar results have been reported elsewhere (e.g., Wolinsky et al., 1993). Although these results are not unexpected, they do have implications for the role of long-term institutional care in the future. Assuming that the admitted resident populations of long-term care facilities will become increasingly old and frail as the population itself ages, it is likely that death rates within institutions will increase as well. In the United States, it is estimated that $20 \%$ of all deaths in 1993 were among residents of nursing homes. It is expected that this figure will rise to $40 \%$ by 2020 (Brock \& Foley, 1998). This, in turn, will have implications for the types of care provided and will shape the very purpose of long-term care facilities. For example, evolution toward an increasingly palliative model of care may be inevitable as the resident population becomes older, increasingly demented, and frailer.

This study is subject to several limitations. Measurement of the dimensions of care is still in a relatively early developmental stage. All of the quality of care measurements in this study are subject to further improvement. To highlight one example, staff training has been shown to be important for optimal resident outcomes (e.g. Teresi et al., 2003). The present study measured this dimension using a series of questions on the provision or non-provision of types of training offered by the facility for different staff groups. These questions did not delve into the actual dementia care knowledge of each participant, not did they look at length of training time, quality of instruction or uptake of course content. Likewise, work experience was not accounted for. This factor may work interactively with availability of courses that provide improved dementia care practices, as well as attendance by each staff member. Attendance and availability may be shaped by the incentives provided by the facility, which in turn would result from the care philosophy employed by the facility administrators, as well as available resources. Additionally, while the sample size was adequate to deal with the question at hand, a larger sample would be desirable. Given the difference in survival probabilities between males and females, it would be of value to collect a sample large enough to complete separate analyses.

From the evidence uncovered in the present study, it appears that social selection is more important than is social causation in determining who will die and who will not, at least during the first 12 months in a long-term care facility. Nonetheless, some evidence for social causation did emerge in the form of facility level physical restraint use. If quality of care (that is, social causative factors) does impact length of life - whether or not it is the purpose of the care provided to lengthen life - care providers, residents and their families should be 
aware of the potential effects of care decisions. That is, even if the stated goal is maximum quality of life without regard for length of life, the risks to length of life produced by any given type or intensity of care should be known.

\section{References:}

Aneshensel, C. S., Pearlin, L. I., Levy-Storms, L., \& Schuler, R. H. (2000). “The transition from home to nursing home mortality among people with dementia.” Journal of Gerontology: Social Sciences, 55B: S152-S162.

Aneshensel, C. S., Pearlin, L. I., Mullan, J. T., Zarit, S. H., \& Whitlatch, C. J. (1995). Profiles of Caregiving: The Unexpected Career. San Diego, CA: Academic Press.

Aneshensel, C. S., Pearlin, L. I., \& Schuler, R. H. (1993). "Stress, role captivity, and the cessation of caregiving." Journal of Health and Social Behavior, 34: 54-70.

Beland, F., \& Zunzunegui, M. V. (1999). "Predictors of functional status in older people living at home." Age and Ageing, 28: 153-159.

Bell, R., \& Krivich, M. (1990). "Effects of type of ownership of skilled nursing facilities on residents' mortality rates in Illinois." Public Health Reports, 105: 515-518.

Belloni-Sonzogni, A., Tissot, A., Tettamanti, M., Frattura, L., \& Spagnoli, A. (1989). "Mortality of demented patients in a geriatric institution." Archives of Gerontology and Geriatrics, 9: 193-197.

Booth, T., Phillips, D., Barritt, A., Berry, S., Martin, D. N., \& Melotte, C. (1983). "Patterns of mortality in homes for the elderly." Age and Ageing, 12: 240-244.

Bracco, L., Gallato, R., Grigoletto, F., Lippi, A., Lepore, V., Bino, G., Lazzaro, M. P., Carella, F., Piccolo, T., Pozzilli, C., Giometto, B., \& Amaducci, L. (1994). "Factors affecting course and survival in Alzheimer's disease: A 9-year longitudinal study." Archives of Neurology, 51: 1213-1219.

Bradley, L., Siddique, C. M., \& Dufton, B. (1995). "Reducing the use of physical restraints in long-term care facilities." Journal of Gerontological Nursing, September, 21-34. 
Quality of Care and Mortality

Among Long-term Care Residents with Dementia

Branch, L. G., \& Jette, A. M. (1982). “A prospective study of long-term care institutionalization among the aged." American Journal of Public Health, 6: 1373-1379.

Brauer, E., Mackeprang, B., \& Bentzon, M. W. (1978). "Prognosis of Survival in a Geriatric Population." Scandinavian Journal of Social Medicine, 6: $17-24$.

British Columbia Vital Statistics Agency. (2001).

Brock, D. B. and D. J. Foley. (1998). "Demography and epidemiology of dying in the U.S. with emphasis on deaths of older persons." Hospital

Journal, 13: 49-60

Bruce, M. L., Hoff, R. A., Jacobs, S. C., \& Leaf, P. L. (1995). "The effects of cognitive impairment on 9-year mortality in a community sSample." Journal of Gerontology: Psychological Sciences, 50B: P289-P296.

Canadian Study of Health and Aging. (1994). "Canadian study of health and aging: Study methods and prevalence of dementia." Canadian Medical Association Journal, 150: 899-913.

Capezuti, E., Strumpf, N., Evans, L., \& Maislin, G. (1999). “Outcomes of nighttime physical restraint removal for severely impaired nursing home residents." American Journal of Alzheimer's Disease, 14: 157 164.

Chappell, N. L., \& Reid, R. C. (2000). "Dimensions of care for dementia sufferers in long-term care institutions: Are they related to outcomes?" Journal of Gerontology: Social Sciences, 55B: S234-S244.

Cohen-Mansfield, J., \& Marx, M. S. (1989). "Do past experiences predict agitation in nursing home residents?" International Journal of Aging and Human Development, 28: 285-294.

Costello, J. P., \& Tanaka, G. M. (1961). Mortality and morbidity in long-term institutional care for the elderly. Journal of the American Geriatrics Society, 9: 959-963.

Coulson, I. (1993). "The impact of the total environment in the care and management of dementia." The American Journal of Alzheimer's Care and Related Disorders \& Research, May/June, 18-25. 
Crockett, D. J., Coval, M., Tuokko, H., Buree, B., \& Koch, W. (1991). Multifocus Assessment Scale for the Frail Elderly-Revised Form (MAS-R) (Procedure Manual). Vancouver, British Columbia: Department of Psychology, University Hospital, University of British Columbia.

Diesfeldt, H. F. A., van Houte, L. R., \& Moerkens, R. M. (1986). "Duration of survival in senile dementia.” Acta Psychiatrica Scandinavia, 73: 366371.

Engle, V. F., \& Graney, M. J. (1993). "Predicting outcomes of nursing home residents: Death and discharge home." Journal of Gerontology: Social Sciences, 48: S269-S275.

Goldfarb, A. I. (1969). "Predicting mortality in the institutionalized aged." Archives of General Psychiatry, 21: 172-175.

Greene, V. L., \& Ondriche, J. I. (1990). "Risk factors for nursing home admissions and exits: A discrete-time hazard function approach." Journal of Gerontology: Social Sciences, 45: S250-S258.

Hill, J., Forbes, W. F., Berthelot, J.-M., Lindsay, J., \& McDowell, I. (1996). "Dementia among seniors." Health Reports, 8: 7-10.

Holmes, D., Splaine, M., Teresi, J., Ory, M., Barrett, V., Monaco, C., \& Ramirez, M. (1994). "What makes special care special: Concept mapping as a definitional tool." Alzheimer's Disease and Associated Disorders, 8 (Suppl. 1): S41-S53.

Kane, R. L., Bell, R., Riegler, S. Z., Wilson, A., \& Keeler, E. (1983). "Predicting the outcomes of nursing-home residents." The Gerontologist, 23: 200-206.

Kelman, H. R., \& Thomas, C. (1990). "Transitions between community and nursing home residence in an urban elderly population." Journal of Community Health, 15: 105-122.

Lichtenstein, M. J., Federspiel, C. F., \& Schaffner, W. (1985). "Factors associated with early demise in nursing home residents: A case-control study." Journal of the American Geriatrics Society, 33: 315-319. 
Quality of Care and Mortality

Among Long-term Care Residents with Dementia

Linn, M. W., Gurel, L., \& Linn, B. S. (1977). "Patient outcome as a measure of quality of nursing home care." American Journal of Public Health, 67: 337-344.

Luchins, D. J., Hanrahan, P., \& Murphy, K. (1997). “Criteria for enrolling dementia patients in hospice." Journal of the American Geriatrics Society, 45: 1054-1059.

Miles, S. H., \& Irvine, P. (1992). "Deaths caused by physical restraints." The Gerontologist, 32: 762-766.

Nygaard, H. A., \& Laake, K. (1990). "Lower mortality of demented nursing home residents." Scandinavian Journal of Primary Health Care, 8: 123-126.

Ostbye, T., Steenhuis, R., Wolfson, C., Walton, R., \& Hill, G. (1999). "Predictors of five-year mortality in older Canadians: The Canadian Study of Health and Aging." Journal of the American Geriatrics Society, 47: 1249-1254

Phillips, C. D., Sloane, P. D., Hawes, C., Koch, G., Han, J., Spry, K., Dunteman, G., \& Williams, R. L. (1997). "Effects of residence in Alzheimer disease special care units on functional outcomes." Journal of the American Medical Association, 278: 1340-1344.

Porrell, F., Caro, F. G., Silva, A., \& Monane, M. (1998). “A longitudinal analysis of nursing home outcomes." Health Services Research, 33: 835-865.

Saxton, J., Silverman, M., Ricci, E., Keane, C., \& Deeley, B. (1998).

"Maintenance of mobility in residents of an Alzheimer special care facility." International Psychogeriatrics, 10: 213-224.

Shapiro, E., \& Tate, R. (1988). "Survival patterns of nursing home admissions and their policy implications." Canadian Journal of Public Health, 79: 268-274.

Shaughnessy, P., \& Kramer, A. M. (1990). "The increased needs of patients in nursing homes and patients receiving home health care." New England Journal of Medicine, 322: 21-27. 
Spector, W. D., \& Mukamel, D. B. (1998). "Using outcomes to make inferences about nursing home quality." Evaluation in the Health Professions, 21: 291-315.

Temkin-Greener, H., \& Meiners, M. R. (1995). “Transitions in long-term care.” The Gerontologist, 35: 196-206.

Teno, J. M., Landrum,K., \& Lynn, J. (1997). "Defining and measuring outcomes in end-stage dementia." Alzheimer Disease and Associated Disorders, 11 (Suppl. 1): S247-S273.

Teresi, J. A., Morse, A. R., Holmes, D., Yatzkan, E. S., Ramirez, M., Rosenthal, B., \& Kong, J. (2003). "Impact of a low vision intervention on affective state among nursing home residents." Journal of Mental Health and Aging, 9: 73-84.

Tomiak, M., Berthelot, J.-M., Guimond, E., \& Mustard, C. A. (2000). "Factors associated with nursing-home entry for elders in Manitoba, Canada." Journal of Gerontology: Medical Sciences, 55A: M279-M287.

Toner, J., Teresi, J. A., Gurland, B. J., \& Tirumalasetti, F. (1999). “The FeelingTone Questionnaire: Reliability and validity of a direct patient assessment screening instrument for the detection of depressive symptoms in cases of dementia." Journal of Clinical Geropsychology, 5: 63-78.

United States Office of Technology Assessment. (1987). Losing a million minds: Confronting the tragedy of Alzheimer's disease and other dementia. Washington, DC: US Government Printing Office.

van Dijk, P. T. M., Dippel, D. W. J., \& Habbema, J. D. F. (1991). "Survival of patients with dementia." Journal of the American Geriatrics Society, 39: 603-610.

van Dijk, P. T. M., van de Sande, H. J., Dippel, W. J., \& Habbema, D. F. (1992). "The nature of excess mortality in nursing home patients with dementia.” Journal of Gerontology: Medical Sciences, 47: M28-34.

Weiler, P. G., \& Cooper, J. K. (1990). "Investigation of death clusters in a nursing home." Journal of Health and Aging, 2: 395-410. 
Quality of Care and Mortality

Among Long-term Care Residents with Dementia

Wolinsky, F. D., Callahan, C. M., Fitzgerald, J. F., \& Johnson, R. J. (1992). "The risk of nursing home placement and subsequent death among older adults." Journal of Gerontology: Social Sciences, 47, S173S182.

Wolinsky, F. D., Stump, T. E., \& Callahan, C. M. (1997). "Does being placed in a nursing home make you sicker and more likely to die?" In S. L. Willis, K. W. Schaie, \& M. Haywards (Eds.), Societal Mechanisms for Maintaining Competence in Old Age. New York: Springer.

Pp. 94-130. 